\title{
ANAESTHESIOLOGY AS A FUTURE SPECIALTY
}

\author{
Khalid Mahmood, Asad Shamim, Muhammad Umair Khan, Tasneem Alam, Usman Khalid, Asad Ullah Jaffery* \\ Combined Military Hospital Quetta/National University of Medical Sciences (NUMS) Pakistan, *Combined Military Hospital Malir/National University of \\ Medical Sciences (NUMS) Pakistan
}

\section{ABSTRACT}

Objective: To ascertain the various aspects directing the undergraduates at Quetta Institute of medical sciences towards anesthesiology as future profession/specialization.

Study Design: Cross sectional study.

Place and Duration of Study: Quetta Institute of Medical Sciences, Quetta Pakistan, from Mar to Apr 2019.

Methodology: Study was conducted among final year medical students with the help of a printed questionnaire consisting of 15 Multiple Choice Questions. The questionnaire provided the required database to explore various factors that influence undergraduates to select their future specialization based on demography and specialty preferences.

Results: A total of 65 undergraduates completed the response sheet. While $45(68.8 \%)$ participants were females and 20 $(31.2 \%)$ were males, $62(95.4 \%)$ were single (unmarried or divorced) and had no children $63(96.9 \%)$. Medicine proved to be the most favourate specialty with 20 (31.4\%) student opting for it whereas anesthesiology was chosen by $4(6.1 \%)$ students.

Conclusion: Anesthesiology still remains a less popular choice among the medical students of Pakistan particularly Quetta Institute of Medical Sciences due to multifaceted factors. Inferior prestige of the specialty was the most significant factor in deciding against anaesthesiology.

Keywords: Anesthesiology, Profession, Undergraduates.

This is an Open Access article distributed under the terms of the Creative Commons Attribution License (https://creativecommons.org/licenses/by-nc/4.0/), which permits unrestricted use, distribution, and reproduction in any medium, provided the original work is properly cited.

\section{INTRODUCTION}

Anesthesiologists are considered per operative physicians when the patients are undergoing different elective and emergency surgical procedures and provide them care when they are not aware. They induce a state of sedation, paralysis and analgesia collectively termed as general anaesthesia to facilitate the surgical procedures and they are responsible to keep them stable throughout the surgical procedure. On the other hand, regional anaesthesia is another anaesthetic technique practiced by many anaesthesiologists that does not affect the level of consciousness and is confined to a certain part of the body ${ }^{1}$. Although advancements in anaesthesia and surgery started simultaneously after Second World War, anaesthesia training started worldwide including Pakistan in eighties. However, due to limited training slots available, severe national and worldwide shortage of anesthesiologists occurred as described by Seraj et al in their study performed at KSA in $2006^{2}$.

Multiple studies have been conducted worldwide in order to ascertain the mindset of medical students while picking up a specialty for their future. Such a study was conducted in Israel in which Orbachzinger concluded that flexible working conditions and

Correspondence: Dr Khalid Mahmood, Classified Anesthesiologist, Combined Military Hospital, Quetta Pakistan

Received: 05 Nov 2019; revised received: 18 Feb 2021; accepted: 25 Feb 2021 financial benefits led to a greater number of students opting anaesthesia in American group i.e. $12 \%$ vs $0 \%$ in Israeli group 3 . Similarly, Tyagi et al from UCMS Delhi anaesthesia and critical care department concluded in their study conducted in 2012 that financial security $(67.7 \%)$ was the key factor while opting anaesthesia as a future specialty whereas the influence of doctorpatient relationship was minimal ${ }^{4}$. Gender of the students proved to be another important factor having females (4 vs 2 ) twice more likely to adapt anesthesio$\operatorname{logy}$ as a specialty as shown by Zulkifli et al in their Malaysian study conducted in 19975 . Similarly a study conducted in Pakistan by Rehman et al, in 2011. Concluded that females were more interested $(9.9 \%$ vs $4.5 \%)$ in pursuing anaesthesia as medical practitioners ${ }^{6}$.

However, limited work has been done in Pakistan to understand the various factors influencing the undergraduates in choosing anesthesiology as future career specialty.

The aim of this study was to understand the pros and cons of the specialty from a student's perspec-tive enabling us to ascertain the factors influencing the undergraduates in choosing anesthesia as future career. Moreover, this will help us address the drawbacks of the specialty (as perceived by medical students) wherever possible, making the specialty more attractive for medical students to choose and practice in future, thus overcoming the acute national shortage. 


\section{METHODOLOGY}

A cross-sectional study was carried out at Quetta Institute of Medical Sciences, Quetta, Pakistan, from March 2019 to April 2019. Institutional Ethical Review Board approved the study vide letter number 23-05/ READ-IRB/001. Informed consent was obtained from all recruited students. The questionnaire was developed after a thorough literature search on similar works. The questionnaire was dispersed among all the fifth year medical students present in the class, to be completed without declaring identity. All final year medical students present in the class were included in the study. The students absent from the class those days were excluded from the study. The sample size was calculated based on a similar previous study ${ }^{7}$, using openepi. Com with a confidence interval of $95 \%$ and $5 \%$ margin of error. The total available strength of the target class was 65 students. Consecutive sampling was utilized for sampling purposes.

Information was gathered through a written set of 15 items questionnaire which was ratified through pilot study. The research details were clarified to the recruited students. The questionnaire consisted of statistical data regarding population attributes, specialization priorities, what characteristics fascinate Pakistani medical students to select their favored specialization and how they consider selecting anaesthesia as a profession. The questionnaire was handed over to the students during the problem-based learning sessions and formal lectures, and, gathered 15 minutes later.

Microsoft Excel was utilized to record the acquired information, and all data analysis was carried out using SPSS-21. The descriptive statistical analyses were performed for the research study variables, and indicated as number and percentage.

\section{RESULTS}

A total of 65 students filled the questionnaire. Descriptive statistics of the participants were shown in table-I. Of those who participated in the study, majority students $44(67.7 \%)$ were females. Most of them were singles $62(95.4 \%)$ and had no children $63(96.9 \%)$. The specialty interest was found to be: $20(30.7 \%)$ internal medicine, $13(20 \%)$ surgery, 12 (18.46\%) obstetrics and gynecology, 5 (7.6\%) pediatrics and $15(23.1 \%)$ other fields (including 4 (6.1\%) anesthesiology).

Based on information depicted in the table-III from student's responses to the questionnaire we can draw the inference that overall, mandatory clinical rotations had negligible impact on students opting in favor of anesthesiology as $60(92.3 \%)$ of respondents had a compulsory clinical rotation in anesthesiology and despite this fact they had no plan of joining anesthesiology. Certain other factors that were very much likely to persuade the medical students of Quetta Institute of Medical Sciences in favor of specialty were the residents in the department 16 (24.6\%), family expectations $28(43 \%)$ and teachers in various departments 21 (32.3\%). Another obvious and significant finding was lack of doctor-patient interaction/relationship against the specialty $35(53.8 \%)$ while a small number $11(17 \%)$ thought there are not enough areas for research in this specialty. However, the surprising and most significant finding was that nearly half $34(52.3 \%)$ responded that the inferior prestige of the specialty when compared to other major specialties compel them against the choice for anesthesiology (most likely due to lack of knowledge about the role of anaesthesiology and its sub specialties in overall clinical management spectrum).

Table-I: Demographic Profile of participants $(n=65)$.

\begin{tabular}{l|c}
\hline \multicolumn{1}{l}{ Variables } & $\mathbf{n}(\%)$ \\
\hline Gender & $21(32.3)$ \\
\hline Boys & $44(67.7)$ \\
\multicolumn{1}{c}{ Girls } & $3(4.6)$ \\
\hline Marital Status & $62(95.4)$ \\
\hline Couples \\
Bachelors \\
\hline Off-Springs \\
\hline Present \\
Absent & $2(3.1)$ \\
\hline \multicolumn{2}{l}{ Table-II: Specialty preferences. } \\
\hline Specialty \\
\hline Medicine \\
Surgery \\
Gynaecology/Obstetrics & $\mathbf{n}(\%)$ \\
Pediatrics & $13(30.7)$ \\
Anesthesiology & $12(18.4)$ \\
Others & $5(7.6)$ \\
\hline
\end{tabular}

Our study findings also revealed that salary/ extra allowance was not significantly contributing to influence the mindset of students to pursue anesthesiology as a future specialty $41(63 \%)$ of the respondents). Finally, respondents reported their priorities regarding specialty selection based on: 35 (53.8\%) doctor-patient relationship, 28 (43\%) pressure from family and peers, $11(17 \%)$ academic/research aspects, and only $9(14 \%)$ income related aspects as $41(63 \%)$ were not persuaded to join anaesthesia even after an extra allowance of salary by the government). 
Table-III: Questionnaire to ascertain specialty selection $(n=65)$.

\begin{tabular}{|c|c|}
\hline Questions (Variables) & n $(\%)$ \\
\hline \multicolumn{2}{|c|}{$\begin{array}{l}\text { Q1. Would you intend to follow anaesthesia as a } \\
\text { postgraduate subject? }\end{array}$} \\
\hline $\begin{array}{l}\text { Agreed } \\
\text { Not agreed }\end{array}$ & $\begin{array}{c}04(6.1 \%) \\
61(93.9 \%)\end{array}$ \\
\hline \multicolumn{2}{|c|}{$\begin{array}{l}\text { Q2. Is it obligatory or optional to attend Anaesthesia } \\
\text { department rotation during } 5 \text { th year of MBBS? }\end{array}$} \\
\hline $\begin{array}{l}\text { It is obligatory } \\
\text { It is optional }\end{array}$ & $\begin{array}{c}60(92.3 \%) \\
05(7.7 \%) \\
\end{array}$ \\
\hline \multicolumn{2}{|l|}{ Q3. If yes, how long was the rotation? } \\
\hline $\begin{array}{l}14 \text { days } \\
28 \text { days } \\
\text { More than } 30 \text { days }\end{array}$ & $\begin{array}{c}58(89.2 \%) \\
05(7.7 \%) \\
02(3.0 \%)\end{array}$ \\
\hline \multicolumn{2}{|c|}{$\begin{array}{l}\text { Q4. Do you have an essential component in examination } \\
\text { syllabus related to anaesthesia? }\end{array}$} \\
\hline $\begin{array}{l}\text { Yes } \\
\text { No }\end{array}$ & $\begin{array}{l}41(63.0 \%) \\
24(36.9 \%)\end{array}$ \\
\hline \multicolumn{2}{|c|}{$\begin{array}{l}\text { Q5. What did you decide after the clinical rotation in } \\
\text { anaesthesia? }\end{array}$} \\
\hline $\begin{array}{l}\text { In favor of specialty } \\
\text { Against specialty } \\
\text { Already chosen my favourate subject for } \\
\text { post-graduation. }\end{array}$ & $\begin{array}{c}03(4.6 \%) \\
62(95.3 \%)\end{array}$ \\
\hline
\end{tabular}

Q6. Which years in med school have enabled you to decide your future specialty?

\begin{tabular}{|c|c|}
\hline $\begin{array}{l}\text { Initial years } \\
\text { Middle years } \\
\text { Final Year }\end{array}$ & $\begin{array}{l}06(9.2 \%) \\
07(10.8 \%) \\
52(80.0 \%)\end{array}$ \\
\hline \multicolumn{2}{|c|}{$\begin{array}{l}\text { Q7. Which individuals have enabled/influenced you to } \\
\text { decide your future specialty? }\end{array}$} \\
\hline $\begin{array}{l}\text { Close relatives } \\
\text { Teachers } \\
\text { Trainees is respective field }\end{array}$ & $\begin{array}{c}28(43.07 \%) \\
21(32.3 \%) \\
16(24.61 \%) \\
\end{array}$ \\
\hline \multicolumn{2}{|c|}{$\begin{array}{l}\text { Q8. What specialty characteristics/attractions have } \\
\text { enabled you to choose in favor of a career? }\end{array}$} \\
\hline $\begin{array}{l}\text { Availability of free time for other tasks } \\
\text { Financial benefit } \\
\text { Patient-physician interaction probability } \\
\text { Research opportunities }\end{array}$ & $\begin{array}{l}10(15.3 \%) \\
09(13.8 \%) \\
35(53.8 \%) \\
11(16.9 \%)\end{array}$ \\
\hline \multicolumn{2}{|c|}{$\begin{array}{l}\text { Q9. Does the workload related to the field affect your } \\
\text { choice? }\end{array}$} \\
\hline $\begin{array}{l}\text { Yes it affects } \\
\text { It does not affect }\end{array}$ & $\begin{array}{l}39(60.0 \%) \\
26(40.0 \%)\end{array}$ \\
\hline \multicolumn{2}{|c|}{$\begin{array}{l}\text { Q10. Does an extra allowance of salary announced by the } \\
\text { MOH Pakistan attracted you to select residency in } \\
\text { anesthesiology? }\end{array}$} \\
\hline $\begin{array}{l}\text { Extra allowance attracted me } \\
\text { Extra allowance did not affect my choice }\end{array}$ & $\begin{array}{c}24(36.9 \%) \\
41(63.07 \%)\end{array}$ \\
\hline \multicolumn{2}{|c|}{ Q11. Are you aware of world anaesthesia day? } \\
\hline $\begin{array}{l}\text { Yes } \\
\text { No }\end{array}$ & $\begin{array}{c}2(3.1 \%) \\
63(96.9 \%) \\
\end{array}$ \\
\hline \multicolumn{2}{|c|}{ Q12. Are you aware of various sub-fields of anaesthesia? } \\
\hline $\begin{array}{l}\text { Yes } \\
\text { No }\end{array}$ & $\begin{array}{l}10(15.38 \%) \\
55(84.62 \%)\end{array}$ \\
\hline
\end{tabular}

Q13. Which sub-filed may motivate you to select anaesthesia as your postgraduate field.

\begin{tabular}{l|c} 
Pain medicine & $40(61.53 \%)$ \\
Intensive care & $22(33.84 \%)$ \\
Cardio- anaesthesia & $03(4.61 \%)$ \\
\hline
\end{tabular}

Q14. Does general perception about anaesthesia and its sub-specialties pushes you to perceive an inferior prestige of specialty compared to others?

\begin{tabular}{l|c}
\begin{tabular}{l|l} 
Yes \\
No
\end{tabular} & $34(52.30 \%)$ \\
& $31(47.70 \%)$ \\
\hline $\begin{array}{l}\text { Q15. Would you select Anaesthesia as a last resort in case } \\
\text { of unsuccessful attempt in pursuing other medical fields. }\end{array}$ \\
\hline Yes & $31(47.69 \%)$ \\
No & $34(52.30 \%)$ \\
\hline
\end{tabular}

\section{DISCUSSION}

The main objective of our descriptive study was to evaluate the perceptions of medial students with regard to anaesthesia as a preferred specialty in future. The reasons varied from one individual to another individual but somehow certain common factors such as prestige of specialty, doctor-patient relationship, research opportunities and modifiable lifestyle were found to be important elements in the decision making process.

Anaesthesia was found to be within the least $4(6.1 \%)$ popular specialties among the students of Quetta Institute of Medical Sciences, Quetta, however Internal Medicine 20 (30.7\%), Gynecology/Obstetrics $12(18.46 \%)$, Surgery $13(20 \%)$, Pediatrics $5(7.6 \%)$, and others $11(16.9 \%)$ were the top ranking popular specialties among the students locally. Surprisingly, interest of medical students in radiology $(0.3 \%)$ is less than anesthesiology $(6.1 \%)$ and a possible explanation of an improved profile of anesthesiology here compared to radiology could be because of a mandatory anaesthesia clinical rotation introduced in this medical college. Lack of doctor-patient relationship or physician-patient interaction probability was an important consideration for majority of respondents $35(53.8 \%)$ in selecting against the anaesthesia specialty. Literature review on impact of Patient-doctor interaction probability on specialty selection revealed variable results with a study by Rahman et al conducted at UAE in $2016^{8}$, showing $12 \%$ student,s choices of specialty influenced by this factor whereas another study by Grasreiner et $a l^{9}$, has revealed that $47 \%$ students choices of specialty were influenced by this factor.

The contribution of prestige or respect of the specialty in the community, in selecting a specialty was $52 \%$ in our study. This factor affected $45 \%$ students in choosing their specialty as shown by Al-Khilaiwi et al 
in their study conducted at King Saud bin Abdulaziz University for Health Sciences (KSAU-HS) Saudi Arbia in $2018^{10}$. Only $37 \%$ of the respondents in our study were persuaded by financial security and extra allowance by the Government of Pakistan. Similarly, Imran et al in their study conducted in Karachi, Pakistan found that financial reward could influence $13 \%$ of the respondents in favor of specialty ${ }^{11}$. Unfortunately, $15.3 \%$ of the students in our study reported that lack of controllable lifestyle or finding free time to manage other tasks was an important issue in deciding against anaesthesiology as future specialty. Similar study conducted by Yang et al, in their Metaanalysis and Systematic review showed that for 53\% students controllable lifestyle or flexible work schedule was important in deciding for/against a specialty 12. Personality on the other hand had no significant influence on career choices as concluded by Chai et al in a Malaysian study conducted in $2018^{13}$. Presence of Research opportunities was important to $16.9 \%$ in our study whereas Nemri et al, at King Abdul Aziz University Saudi Arabia in 2015 found that $56.9 \%$ students considered it important in career decision making ${ }^{14}$. Another insight to the mindset of students opting for a specialty was that they were heavily influenced by the faculty members/residents of their respective specialty.

In our study at least $32 \%$ of the responders were influenced by faculty and $25 \%$ of the responders were motivated by the residents of the specialty as compared to Khader who found that only $11.1 \%$ of medical students considered the advice of a faculty member ${ }^{15}$. A study conducted by Alkhaneen et al, in Riyadh, Suudi Arabia, in 2018 found that the influence of mentors on specialty choice was low in all four groups studied, (ANOVA F 2.93, $p$-value 0.033) ${ }^{16}$. However, it was ranked as the second most influential factor on medical students' choice of a career in EM and the first most influential factor for their choice of other specialties in US medical colleges as shown by Boyd et al in their study conducted at USA in 200917. The clinical role models are significant elements of the specialty related decision making process within the students as compared to the influence of family members. Kamat et al in his study conducted in India in 2015 found only $9.4 \%$ of participants preferring family opinion for choosing a specialty ${ }^{18}$.

\section{CONCLUSION}

Anesthesiology still remains a less popular choice among the medical students of Pakistan particularly
Quetta Institute of Medical Sciences due to multifaceted factors. This has led to an extreme shortage of trained anesthesiologist nationwide especially in peripheries. Efforts should be made to announce joining anesthesiology as a part of national cause that can address the problem. Moreover, strategies should be developed to bring forward and enhance the attractiveness of the specialty using means of telecommunication, social media and conferences that can further elevate the prestige of specialty/sub specialties.

Moreover, all the faculty members and residents of anesthesiology should strive hard to improve the profile of specialty by having more interactions with students at foundation level persuading them for anesthesiology and clearing misconceptions.

\section{CONFLICT OF INTEREST}

This study has no conflict of interest to be declared by any author.

\section{REFERENCES}

1. Al Khilaiwi RM, Alatassi A, Almohawis AH, Alhumaid TA, Almazyad KA, Bustami RT. Medical students' attitude toward anesthesia as a future career. Saudi J Anaesth 2018; 12(2): 215-9.

2. Seraj M. The Status of anaesthesia services and residency training programmes in Saudi Arabia: Facts and personal prospective. Internet J Anesthesiol 2006; 15(1): 1-10.

3. Orbach-Zinger S, Rosenblum R, Svetzky S, Staiman A, Eidelman LA. Attitudes to anesthesiology residency among medical students in the American and the Israel programs at sackler faculty of medicine, Tel Aviv University. Isr Med Assoc J 2011; 13(8): 485-7.

4. Tyagi A, Kumar S, Sethi AK, Dhaliwal U. Factors influencing career choices in anaesthesiology. Indian J Anaesth 2012; 56(4): 342-7.

5. Zulkifli A, Rogayah J. Career preferences of male and female medical students in Malaysia. Med J Malaysia 1997; 52(1): 76-81.

6. Rehman A, Rehman T, Shaikh MA, Yasmin H, Asif A, Kafil H, et al. Pakistani medical students' specialty preference and the influencing factors. J Pak Med Assoc 2011; 61(7): 713-8.

7. Asani MO, Gwarzo GD, Gambo MJ. Preference of specialty choices among final year medical students of Bayero University Kano. Sahel Med J 2016; 19(3): 155-8.

8. Abdulrahman M, Makki M, Shaaban S, Al Shamsi M, Venkatramana $\mathrm{M}$, Sulaiman $\mathrm{N}$, et al. Specialty preferences and motivating factors: A national survey on medical students from five UAE medical schools. Educ Health 2016; 29(3): 231-43.

9. Grasreiner D, Dahmen, Settmacher U. Specialty preferences and influencing factors: a repeated cross-sectional survey of first- to sixth-year medical students in Jena, Germany. BMC Med Educ 2018; 103(18): 1200-8.

10. AlKhilaiwi RM, Alatassi A, Almohawis AH, Alhumaid TA, Almazyad KA, Bustami RT. Medical students' attitude toward anesthesia as a future career. Saudi J Anaesth 2018; 12(2): 215-9.

11. Imran S, Noreen K, Nadia K, Riasat AN, Kauser AK. Reasons for choosing specialty after graduation among students of a private medicalcollege in pakistan. Pak J Health 2017; 7(2): 90-4.

12. Yang $Y, \mathrm{Li} \mathrm{J}, \mathrm{Wu} X$, Wang J, Wangting $\mathrm{L}$, Zhu $\mathrm{Y}$, et al. Factors influencing subspecialty choice among medical students: a systematic review and meta-analysis. BMJ Open 2019; 9(1): e022097. 
13. Chai WY, Chitra B, Sundaram DM, Eric TYL, Pin TW, Soe HHK. Factors influencing medical student's choices of future specialization in medical sciences: a cross sectional study. Am J Edu Res 2018; 4(4): 168-9.

14. Nemri IA. Factors affecting the specialty choice of medical students at king Abdulaziz University in Jeddah, Saudi Arabia Community Med Public Health 2015; 2(4): 570-5.

15. Khader Y, Al-Zoubi D, Amarin Z, Alkafagei A, Khasawneh M. Factors affecting medical students in formulating their specialty preferences in Jordan. BMC Med Educ 2008; 8(1): 32-36.

16. Alkhaneen $\mathrm{H}$, Alhusain $\mathrm{F}$, Alshahri $\mathrm{K}, \mathrm{Al}$ Jerian N. Factors infl- uencing medical students' choice of emergency medicine as a career specialty-a descriptive study of Saudi medical students. Int J Emerg Med 2018; 11(1): 14-18.

17. Boyd JS, Clyne B, Reinert SE, Zink BJ. Emergency medicine career choice: a profile of factors and influences from the Association of American Medical Colleges (AAMC) graduation questionnaires. Acad Emerg Med 2009; 16(6): 544-9.

18. Kamat CA, Todakar M, Rangalakshmi S, Pawan. Awareness about scope of anaesthesiology, attitudes towards the speciality and stress levels amongst postgraduate students in anaesthesiology: A cross-sectional study. Indian J Anaesth 2015; 59(2): 110-7. 